\title{
3D Discrete Macro-Modelling Approach for Masonry Arch Bridges
}

\author{
Salvatore Caddemi, Ivo Caliò, Francesco Cannizzaro, Domenico D’Urso, Bartolomeo Pantò, Davide \\ Rapicavoli
}

Dept. of Engineering and Architecture, University of Catania, Catania (Italy)

\section{Giuseppe Occhipinti}

Italian National Research Council, Institute of Environmental Geology and Geoengineer, Rome (Italy)

Contacting author: icalio@dica.unict.it

\begin{abstract}
conference
Masonry multi-span arch bridges are historical structures still playing a key role in many transportation networks of numerous countries. Most of these bridges are several decades old and have been subjected to continuous dynamic loadings, due to the vehicular traffic, and in many cases their maintenance required structural modifications. The currently adopted health monitoring strategies are based on in situ inspections as well as structural assessments based on numerical models characterised by different levels of reliability according to the required purpose. Simplified approaches are generally adopted for fast structural evaluation, on the other hand more rigorous approaches are fundamental for a reliable structural assessment of these particular structures, often characterized by very complex geometrical layouts and structural alterations not always sufficiently documented. This paper presents an original Discrete Macro-Element Method (DMEM) that allows a reliable simulation of the linear and nonlinear response of masonry structures and masonry bridges characterised by a lower computational burden, compared to classical nonlinear FEM analyses, although maintaining a good accuracy. The method is applied to a real masonry bridges and the results are compared with those obtained from a more sophisticated threedimensional nonlinear FEM model both in linear and nonlinear context.
\end{abstract}

Keywords: Discrete Element Method (DEM), nonlinear analysis, Discrete Macro-Element Method (DMEM), masonry arch bridges, HiStrA software, railway bridges.

\section{Introduction}

Masonry arch bridges represent cultural heritage structures that still play a fundamental role in the national roads and railway infrastructures of many countries. As reported in $[1,2]$ the total number of masonry arch railway bridges and culverts has been estimated to be around 200,000 , only in Europe, being about the $50 \%$ of the total railway European bridge-stock. The continuous upgrading of the railway network, often implying the use of new and faster trains, involves the need to provide a structural assessment of the existing masonry bridges under operational static and dynamic loading. On the other hand, a reliable structural assessment of old masonry arch bridges represents a very complex task for several different reasons. Masonry arch bridges have been constructed according to old design strategies, often based on geometrical consideration, and according to structural details and masonry materials typical of the region of 
construction and of the period of the realization. The original design drawings are rarely available and a great part of the structural elements is inaccessible. On the other, it is important to guarantee the efficiency of the masonry bridges, within an infrastructural network. To this aim different inspection methods are performed to investigate the condition of masonry arch bridges, as reported in the works of Orbán and Gutermann $[1,2]$. In some cases dynamic identification strategies have also been proposed [3]-[6]. Aiming at providing a structural assessment of the bridge, several computational simplified as well as detailed strategies have been proposed in the literature. The proposed procedures are generally based on limit analysis or static nonlinear FEM approaches, some simplified approaches describe arches and piers as nonlinear beam-like elements [7][8]. Some authors proposed 2D finite element or discrete element strategies [9][11], often accounting for the backfill contribution. Full 3D modelling nonlinear approaches are based on rigid element with nonlinear interfaces [12][14] or FEM nonlinear analysis [15][16]. Detailed 3D descriptions have been also recently proposed utilising a mesoscale strategy for brick/blockmasonry [17],[18]. These advanced modelling strategy enables accurate realistic prediction of the structural response of masonry arch bridges under different loading conditions. However, because of the significant computational cost, these detailed simulations need to be coupled with parallel computing resources and require high expert abilities in the modelling and the interpretation of the results.

This paper proposes an original Discrete MacroElement Method (DMEM), alternative to all the previously discussed approaches, for threedimensional simulation of the nonlinear behaviour of masonry arch bridges. This modelling strategy takes advantage of the Discrete Element Method (DEM) approach at a 'macro-scale'. Differently from the classical DEM method, in which each element is considered as a rigid body, in the proposed DMEM strategy each macro-element possesses a shear deformability, simply related to a single degree of freedom for each macro- element. The mechanical interaction among adjacent macro-elements is concentrated in zerothickness cohesive interfaces, incorporating the nonlinear behaviour of masonry, according to a simplified homogenization technique, based on a straightforward fibre calibration along two main directions of the macro-element. The modelling strategy is characterised by a very low computational burden since each macro-element is ruled by seven degrees of freedom only and all the nonlinearities are associated to monodimensional constitutive laws. The proposed DMEM is applied for the simulation of the nonlinear response of a real masonry arch bridges. The results are also compared with those obtained through an homogenised nonlinear FEM simulation by means of a commercial software currently used for masonry bridge modelling. The obtained results highlight the capability of the DME approach to be efficiently used for the structural assessment of masonry arch bridges.

\section{The Adopted Discrete Macro- Element Method (DMEM)}

The three-dimensional macro-element, adopted for modelling masonry arch bridges, has been developed within an innovative simplified macromodelling approach introduced by Caliò et al. for the simulation of the in-plane [19] and out-ofplane [20]-[22] nonlinear response of masonry structure subjected to operational and extreme loadings. The macro-element strategy has been extended to the simulation of the nonlinear behaviour of masonry structures with curved geometry with the introduction of a shell-macroelement able to discretise monumental structures in presence of arches, vaults and domes [23],[24].

A qualitative representation of curved geometry structures modelled as a mesh of macro-element is reported in Figure 1. The kinematics of each macro-element is ruled by seven degrees of freedom (six rigid body motion degrees of freedom and one associated with the in-plane shear deformability). 

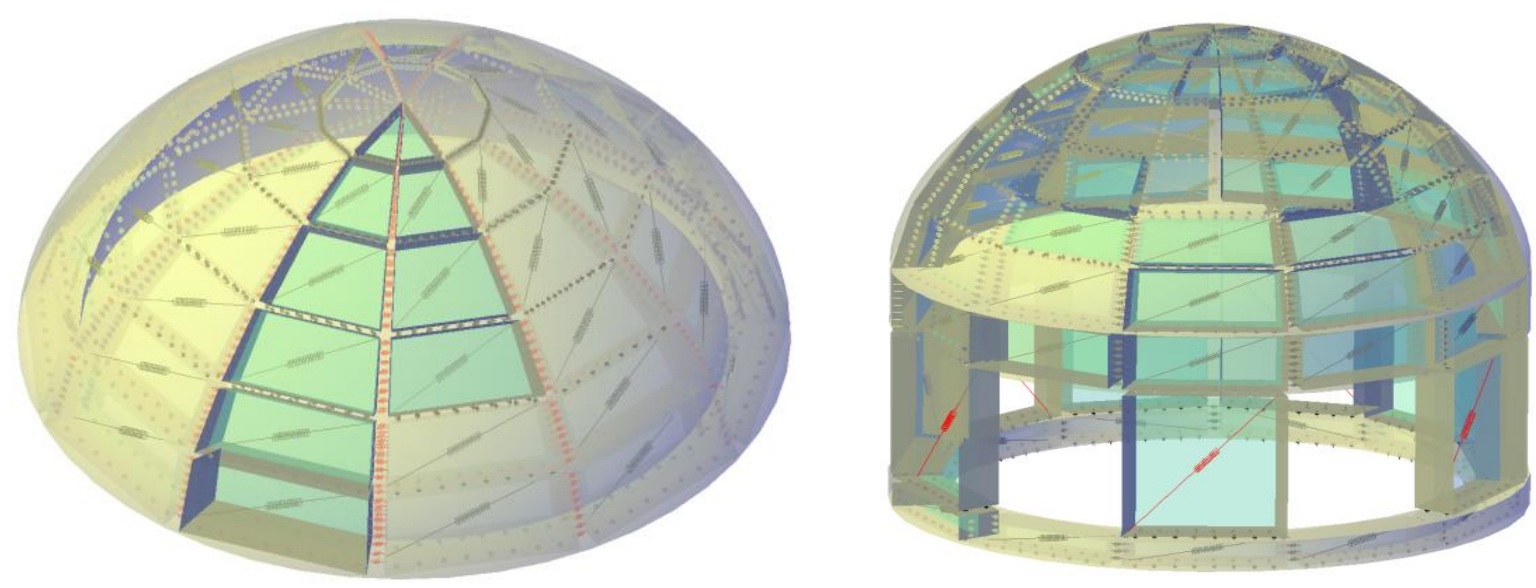

Figure 1: Qualitative examples of subdivision of typical curved shaped masonry structures through the proposed macro-element strategy.

The interfaces between elements are discretised according to transversal nonlinear links calibrated according to a fiber approach. Non-linear sliding links, one along the axis of the interface and two orthogonal to the axis govern the in and out of plane sliding as well as the torsional response of the adjacent elements. A detailed description of the mechanical characterization of this non-trivial shell discrete element is outside the purpose of the present paper that is oriented to a methodological description of this computationally effective approach aiming at demonstrating its suitability for practical applications devoted to the structural assessment of existing masonry arch bridges. More details on the basis of the proposed innovative macroelement strategy are reported in the referenced papers.

\section{Numerical applications}

The proposed DMEM has been implemented in the software HiStrA (Historical Structures Analysis) and extensively validated both in linear and nonlinear, static and dynamics contexts with reference to monumental masonry structures. For applications to masonry arch bridges the method has been implemented in the specific section of code HiStrA-Bridge [25]. The software contains some innovative solutions for modelling typical masonry arch bridges. Several parametrical input tools (wizards) allow an easy input of the full 3D geometry, the mechanical properties, the typical loading conditions and the type of analysis with the aid of graphical preview. It is worth noticing that a parsimonious, sufficiently accurate and user-friendly numerical approach for modelling existing masonry arch bridges represents a key point for the maintenance, the structural assessment and the health monitoring of railways infrastructures.

The application reported in the following aim at providing a validation of the model, both in the linear and nonlinear field, through a comparison with accurate 3D nonlinear FEM simulations.

\subsection{The Bridge under investigation}

The bridge under investigation, Figure 2 , dates back to 20th century, and is located at $\mathrm{km}+21.529$ on the national railway system between Lecco and Colico, over Esino torrent, in the north of Italy. The structural assessment of the bridge, performed by using the software HiStrA bridges, has been conducted together with the excellent cooperation of the engineers G. Pisanelli, G. Spirolazzi, R. Zurlo of the Milano engineering office of Italian National Railway Network Milano.

The five-arches bridge is composed by different masonry typologies, the arches are composed of brick masonry and the piers and the spandrels are characterised by square ashlar masonry. 


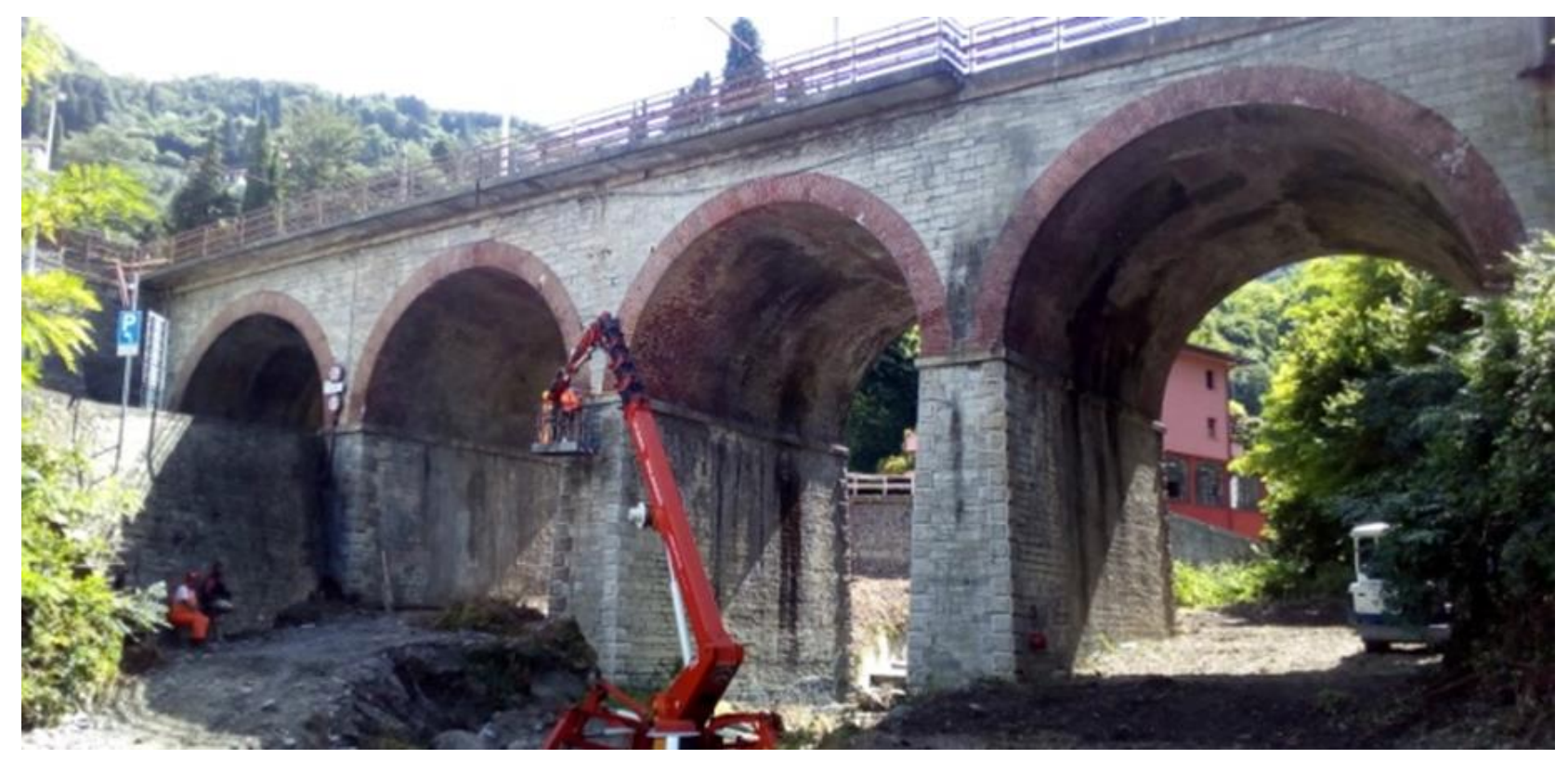

Figure 2: The considered bridge over the Esino torrent

The bridge, whose length is about 50.6 meters and 5.3 meters width, consists of 5 round arches with approximately 8 meters span, supported by 4 piers and two abutments. The spandrel walls, vertically supported on the outer faces of arches and piers, are formed by squared ashlar masonry. The thickness of brick masonry arches is 0.68 meters and the piers are characterized by a linear variation of the rectangular cross section ranging from $2.15 \times 10.87$ meter, at the base, to $1.64 \times 10.37$ meter, at the top. The masonry foundation are constituted by regular parallelepipeds with base of $2.45 \times 11.37$ meter and 1.90 meters height, the two rail-roads are located at about 1.50 meters upon the arch intrados.

\subsection{The mechanical properties of the materials}

In situ experimental survey allowed to identify the geometry of the bridge and of its elements, however no experimental tests have been performed for evaluating the mechanical properties of the masonry. For this reason the numerical simulations reported in the following have been performed by considered average value of the mechanical characteristics for the masonry typologies of the bridge. The backfill properties have been modelled by referring to typical values reported in the scientific literature. Table 1 summarizes the masonry typologies assumed for the different structural elements and relative mechanical properties adopted in the numerical simulations. The behaviour of the bridge has been related to homogeneous properties of the different masonry typologies expressed by the longitudinal elastic modulus $E$, the tangential elastic modulus $G$, and the mass density $w$. Tensile $f_{\mathrm{t}}$ and compressive $f_{\mathrm{c}}$ strengths of the masonry have been related to a linear softening behaviour governed by the corresponding fracture energies $G_{\mathrm{ft}}$ and $G_{\mathrm{fc}}$. The shear diagonal behaviour has been related to a Mohr Coulomb constitutive law characterised by a shear strength $\tau_{0}$ and a friction coefficient $\mu=0.5$. 
Table 1: The mechanical properties adopted in the numerical simulations

\begin{tabular}{lcccccccc}
\hline Elements & $\begin{array}{c}f_{\mathrm{m}} \\
{[\mathrm{MPa}]}\end{array}$ & $\begin{array}{c}\tau_{0} \\
{[\mathrm{MPa}]}\end{array}$ & $\begin{array}{c}E \\
{[\mathrm{MPa}]}\end{array}$ & $\begin{array}{c}G \\
{[\mathrm{MPa}]}\end{array}$ & $\begin{array}{c}w \\
{\left[\mathrm{kN} / \mathrm{m}^{3}\right]}\end{array}$ & $\begin{array}{c}f_{\mathrm{t}} \\
{[\mathrm{MPa}]}\end{array}$ & $\begin{array}{c}G_{\mathrm{ft}} \\
{[\mathrm{N} / \mathrm{mm}]}\end{array}$ & $\begin{array}{c}G_{\mathrm{fc}} \\
{[\mathrm{N} / \mathrm{mm}]}\end{array}$ \\
\hline Abutment, pier, spandrel wall & 5.8 & 0.4 & 2060 & 860 & 22 & 0.12 & 0.02 & 100 \\
\hline Masonry arches & 2.6 & 0.3 & 1200 & 500 & 18 & 0.12 & 0.02 & 100 \\
\hline Backing, fill material, ballast & 1.1 & 0.05 & 700 & 290 & 19 & 0.05 & $\infty$ & 100 \\
\hline
\end{tabular}

\section{DMEM VERSUS FEM}

The DMEM has been implemented in the HiStrABridge software that allows to model typical masonry arch bridge with the aid of a powerful parametric graphical user interface. The applications reported in the following aim at validating the model both in the linear and nonlinear fields through a comparison between the results obtained by the DMEM and a nonlinear FEM simulation.

\subsection{Validation of the model in the linear field}

In Figure 3 a general view of the 3D HiStrA-DME model and LUSAS-FEM models are reported. In the

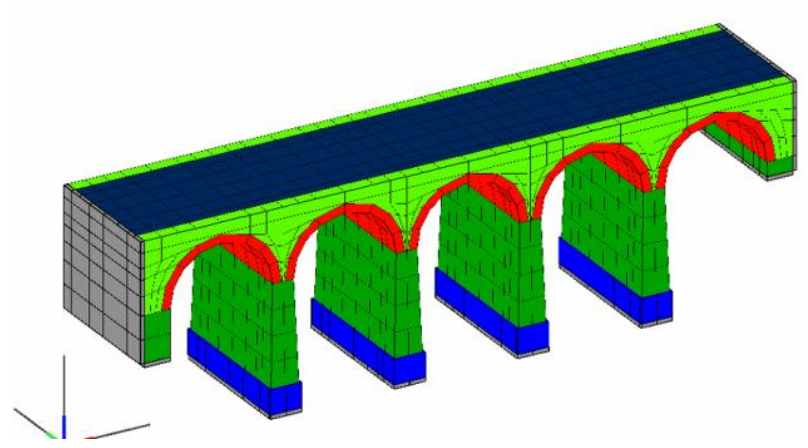

(a)
LUSAS model the HX20K solid element has been adopted for linear and nonlinear simulations [26]. The nonlinear FEM discretisation is consistent to a total number of 12080 solid element corresponding to 349362 degrees of freedom. The ratio of the DMEM/FEM degrees shows that HISTRA-bridge model requires only the 3,5\% degrees of freedom compared to the LUSAS model. In the DMEM, the distribution of mass has been considered by assigning the total mass of each masonry macro-portion to the centre of mass of the corresponding macro-element. The linear eigen-properties, provided by the two models, assuming homogeneous elastic and isotropic material, have been evaluated and compared.

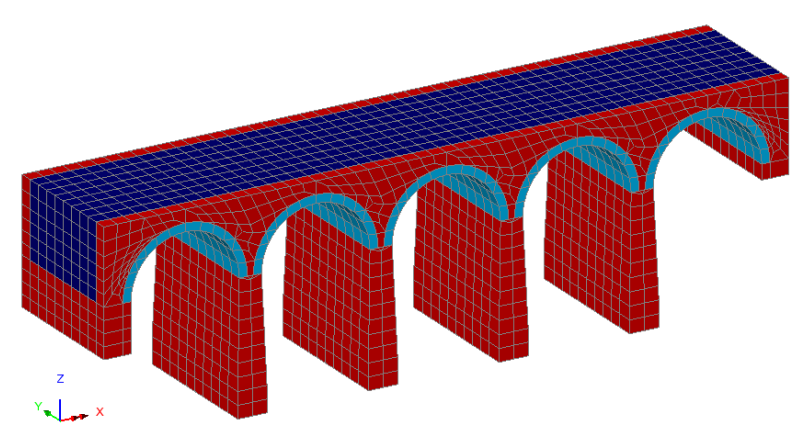

(b)

Figure 3: 3D general views of (a) HISTRA and (b) LUSAS models.

Figure 4 reports the first three vibration mode shapes and the corresponding frequencies. It can be observed how the two models provide very close results, although based on different approaches characterised by a strongly different computational costs. This comparison, performed on the linear elastic context, shows an excellent linear elastic validation between the two approaches. 
HISTRA

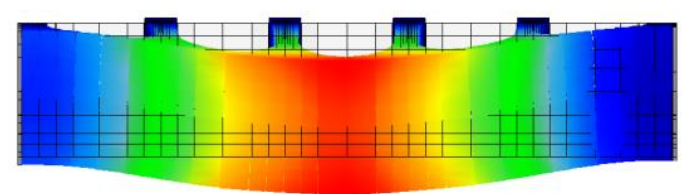

$4.13 \mathrm{~Hz}$

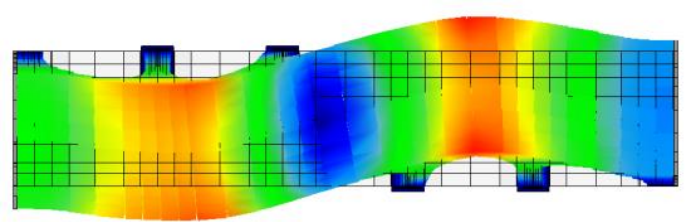

$5.264 \mathrm{~Hz}$

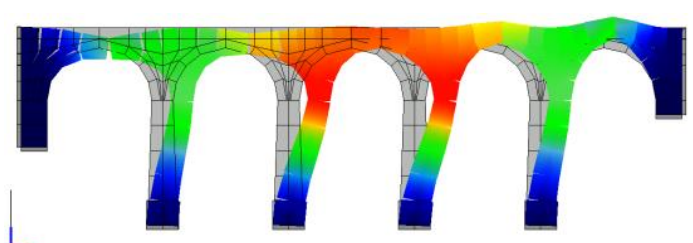

$5.363 \mathrm{~Hz}$
LUSAS

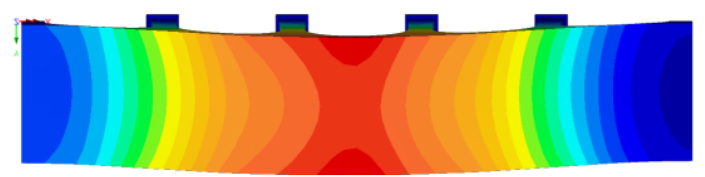

$4.191 \mathrm{~Hz}$

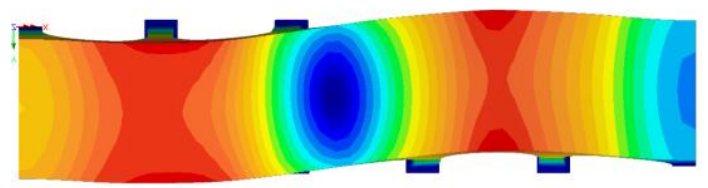

$5.412 \mathrm{~Hz}$

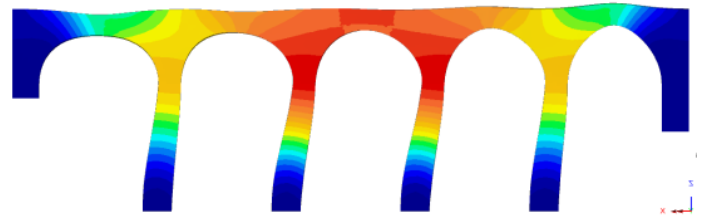

$5.435 \mathrm{~Hz}$

Figure 4: HiStrA-Bridge versus LUSAS. Comparison between the first three vibration frequencies and the corresponding vibration modes.

4.2 Validation of the model in the nonlinear field

In this sub-section a numerical validation of the proposed DMEM, in the nonlinear field, is provided.
Nonlinear static analysis (push-down) corresponding to an anti-symmetric loading condition, as depicted in Figure 5, has been applied.
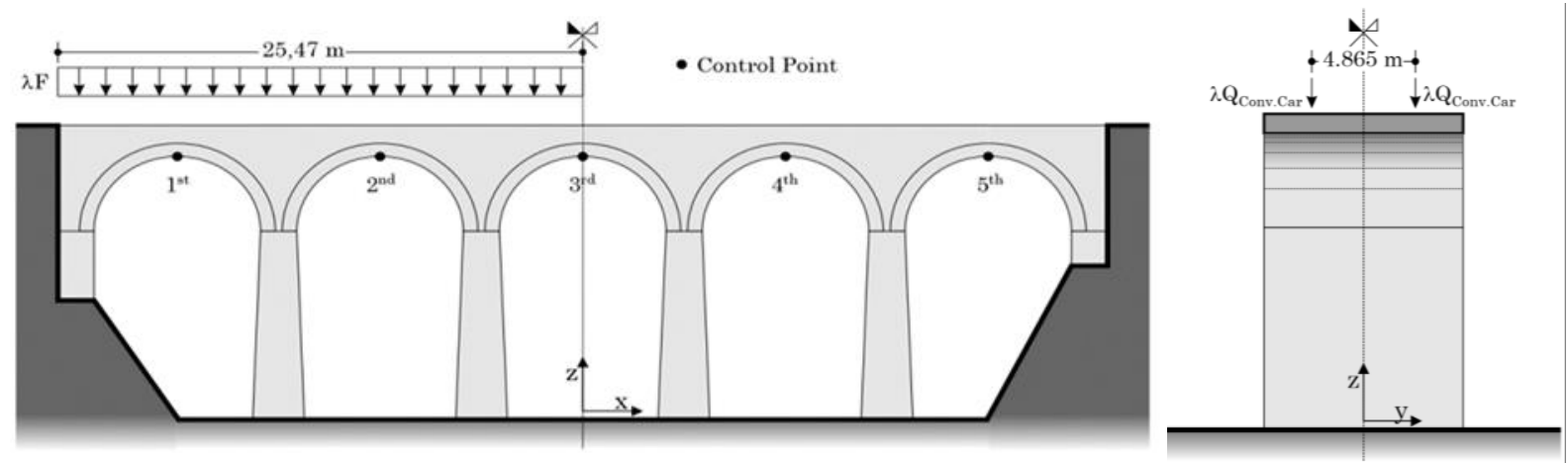

Figure 5: Scheme of the line loads distribution 
Following the code prescriptions for the collapse limit state under vertical loadings [27], the following load combination has been considered

$$
F=1.4 G_{k}+1.5 Q_{\text {conv. Car }}
$$

Being $G_{\mathrm{k}}$ the characteristic value of the selfweight of the bridge and $Q_{\text {Conv.Car }}$ the load of the train convey equal to $72 \mathrm{KN} / \mathrm{m}$. In the performed push-down analysis the model has been subjected
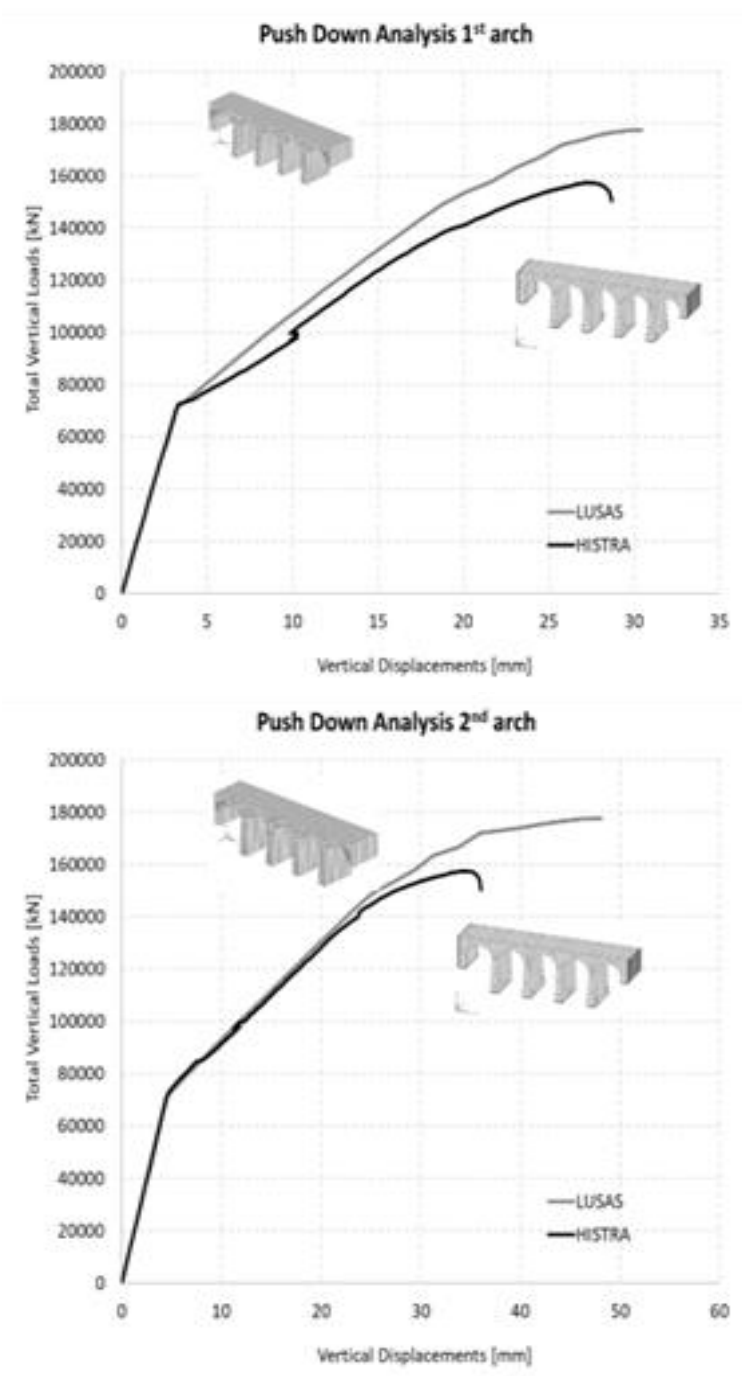

firstly to an incremental analysis of the bridge subjected to its self-weight, amplified by a factor 1.4, and then to an incremental vertical convey load distribution until the ultimate condition has been reached.

$$
F(\lambda)=1.4 G_{k}+\lambda 1.5 Q_{\text {conv. Car })}
$$

The mechanical properties employed in the numerical simulations are reported in Table 1.
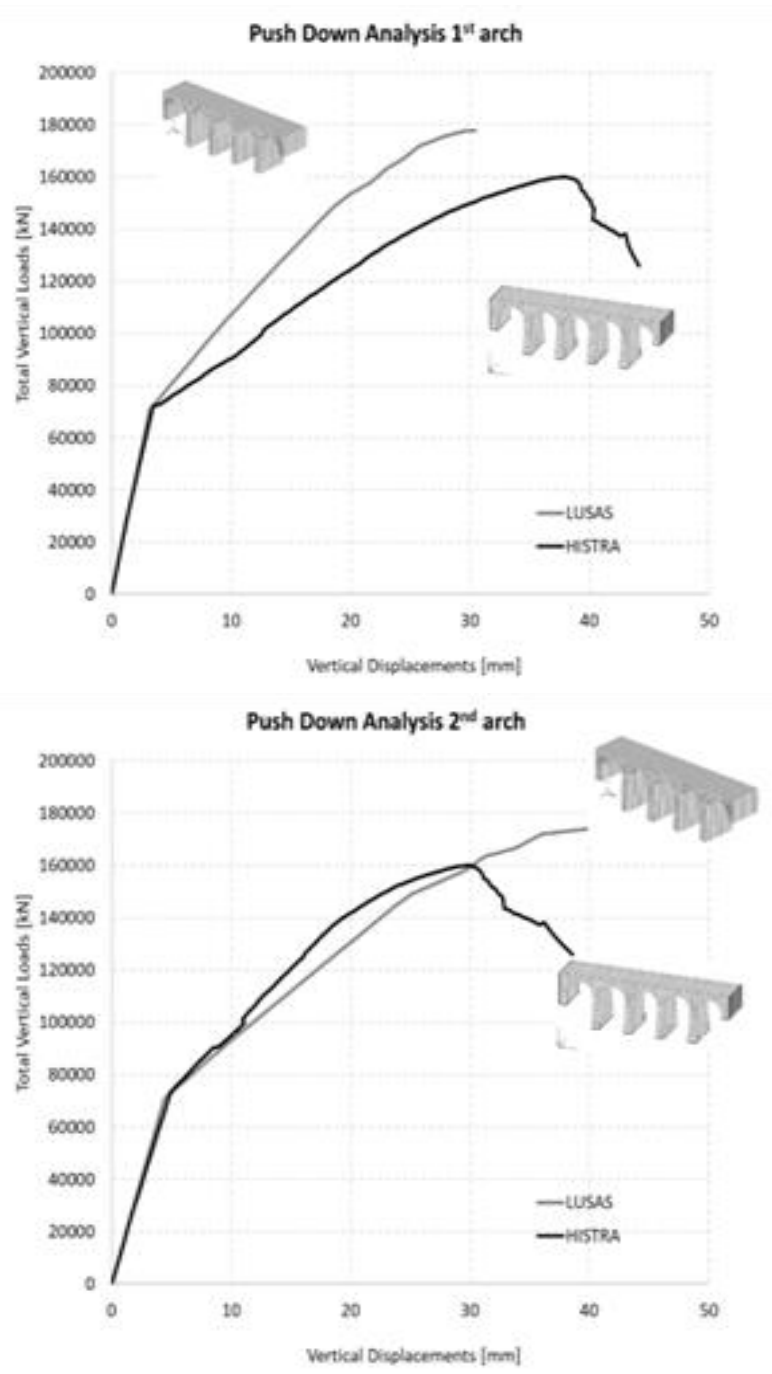

Figure 6: Push-down comparison. DMEM versus FEM, capacity curves for the first two considered target points. (a) results corresponding to shear-diagonal linear elastic behavior; (a) results corresponding to nonlinear shear diagonal behavior as specified in table 1. 

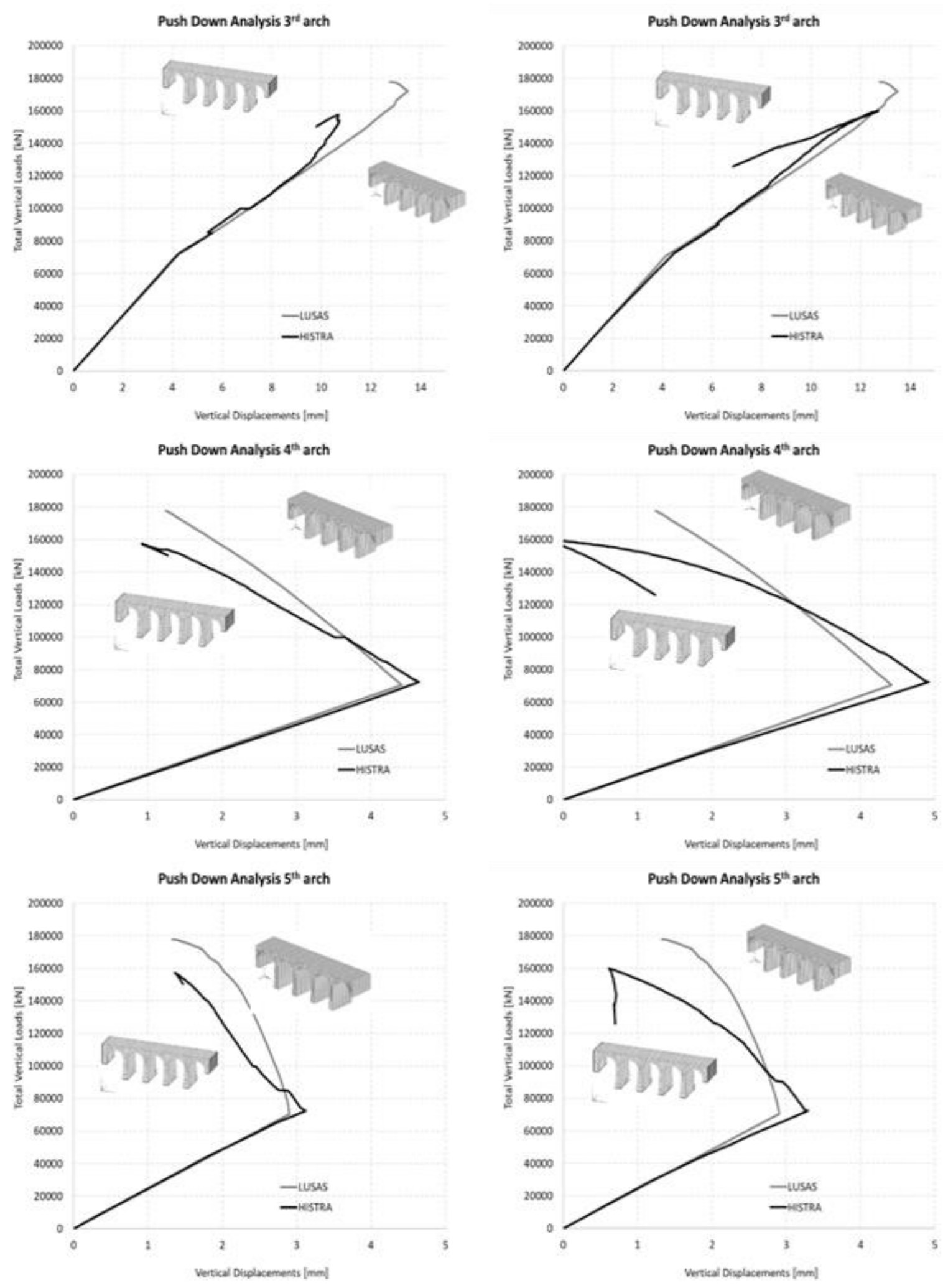

(a)

(b)

Figure 7: Push-down comparison. DMEM versus FEM, capacity curves for the target points 3, 4 and 5. (a) results corresponding to shear-diagonal linear elastic behavior; (a) results corresponding to nonlinear shear diagonal behavior as specified in table 1. 
It is important to specify that the nonlinear FEM model does not require the definition of the shear strength $\tau_{0}$, being the nonlinear behaviour related only to the tensile and compressive strength and to the corresponding fracture energies. In DMEM, the shear diagonal behaviour is governed by internal shear deformability of the element. For this reason in the simulation performed in HiStrA two different analyses have been performed. The first one considering a linear elastic shear diagonal deformation (reported in Figures $6 a$ and $7 a$ ) and the second one assuming a nonlinear shear-diagonal behaviour characterised by a Mohr-Coloumb law with $\tau_{0}$, as reported in table 1 , and friction coefficient $\mu=0.5$ (reported in Figure $6 b$ and $7 b$ ).

Figures 6 and 7 report the total vertical load as a function of the vertical displacement of the 5 target points identified in Figure 5 .

A very good agreement between the DMEM and FEM can be observed. The results obtained by the proposed DMEM appear to be more conservative in terms of ultimate strength although characterised by a more ductile behaviour. As can be observed by comparing Figures $6 a$ and $7 a$ with Figures $6 b$ and $7 b$, The assumption of shear-diagonal nonlinear behaviour leads to a lower strength capacity of the bridge. However, the characterization of the shear diagonal behaviour with a specific constitutive law cannot be performed with the FEM simulation.

It is worth to emphasize that the correct definition of the shear-failure mechanical parameters in a DEM approach as well as the capability of the concrete-based FEM models to correctly predict combined flexural-shear response of masonry structures represent a key numerical issue that should be further investigated.

In Figure 8, the results of the nonlinear static analyses, expressed in terms of deformed shape and damage pattern at collapse, are compared. A good agreement between the two approaches can be observed also in terms of damage scenario prediction.

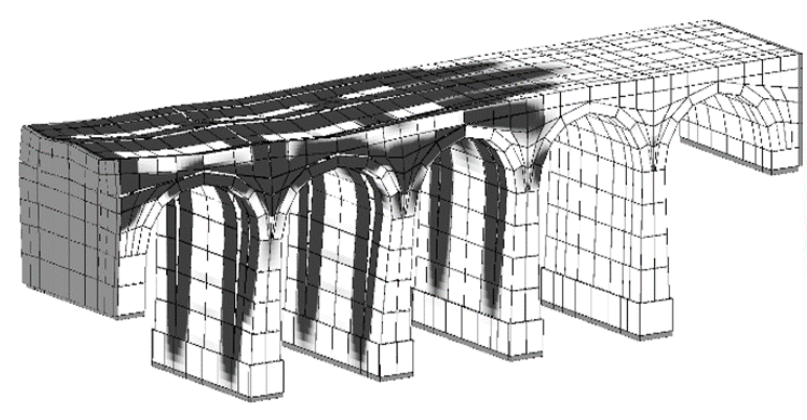

(a)

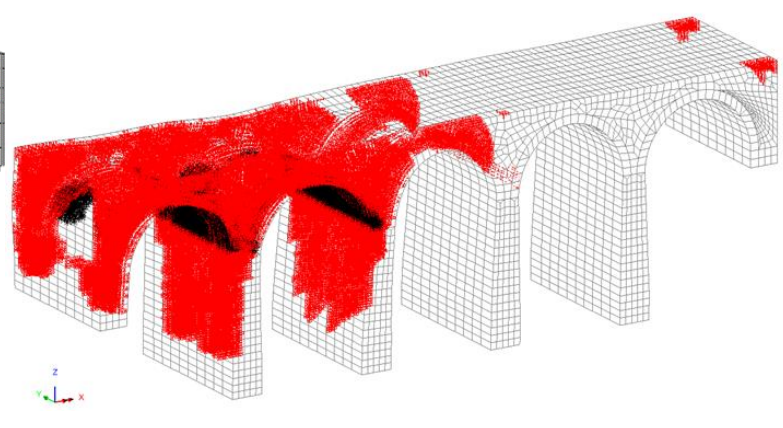

(b)

Figure 8. Push-down comparison. DMEM (a) versus FEM (b), damage scenario, frontal and 3D-view.

\section{Conclusions}

In the present work, a recently introduced discrete three-dimensional macro-element method for curved masonry structure is improved and applied to a typical multi-span masonry railway arch bridges. The model is based on a discrete macro-element approach that allows a reliable simulation of the linear and nonlinear response of masonry bridges with an significant lower computational cost if compared to classical nonlinear FEM analyses. The equivalence between a masonry portion and the corresponding macro-element is geometrically consistent and the element calibration is based on a simple fibre discretisation of the masonry portion leading to a modelling strategy that does not require an expert judgement since the interpretation 
of the numerical results are simple and unambiguous.

The capability of the proposed numerical strategy has been investigated by comparing the results, obtained for a typical masonry bridge, with those provided by nonlinear FEM simulations both in linear dynamic and nonlinear static fields.

\section{ACKNOWLEDGEMENTS}

The authors gratefully acknowledge the financial support of the Ministero dell'Istruzione, dell'Università e della Ricerca (National Research Project PRIN 2015JW9NJT "Advanced mechanical modeling of new materials and structures for the solution of 2020 Horizon challenges").

\section{REFERENCES}

[1] Z. Orban, Assessment, reliability and maintenance of masonry arch railway bridges in Europe. Proc. of ARCH'04, 4th int. conf. on arch bridges, P. Roca, E. Oñate eds., CIMNE, Barcelona, 2004.

[2] Z. Orban, M. Gutermann, Assessment of masonry arch railway bridges using nondestructive in-situ testing methods. Engineering Structures, 31, 2287-2298, 2009.

[3] Benedetti, A., Colla, C., Pignagnoli, G., Tarozzi, M. "Static and Dynamic Investigation of the Taro Masonry Bridge in Parma" Simplified seismic assessment of multi-span masonry arch bridges (2015) Bulletin of Earthquake Engineering, 13 (9), pp. 2629-2646.

[4] Sarhosis, V., De Santis, S., de Felice, G. "A review of experimental investigations and assessment methods for masonry arch bridges" (2016) Structure and Infrastructure Engineering, 12 (11), pp. 1439-1464.
[5] Brencich, A., Sabia, D. "Experimental identification of a multi-span masonry bridge: The Tanaro Bridge" (2008) Construction and Building Materials, 22 (10), pp. 2087-2099.

[6] Gentile, C. "Modal and structural identification of a R.C. arch bridge" (2006) Structural Engineering and Mechanics, 22 (1), pp. 53-70.

[7] A. Cavicchi, L. Gambarotta, Lower bound limit analysis of masonry bridges including arch-fill interaction, Eng. Struct. 29 (2007) 3002-3014.

[8] G. de Felice, Assessment of the loadcarrying capacity of multi-span masonry arch bridges using fibre beam elements, Engineering Structures, 31(8), 16341647, 2009.

[9] A. Audenaert, P. Fanning, L. Sobczak, H. Peremans, 2-D analysis of arch bridges using an elasto-plastic material model, Eng. Struct., 30, 845-55, 2008.

[10] M. Gilbert, C. Casapulla, H.M. Ahmed, Limit analysis of masonry block structures with non-associative frictional joints using linear programming, Computers \& Structures, 84(13-14), 873-887, 2006

[11] Gilbert M. Ring: a 2D rigid block analysis program for masonry arch bridges. In: Proc. 3rd international arch bridges conference, Paris, France; 2001: 109118.

[12] E. Reccia, G. Milani, A. Cecchi, A. Tralli, Full 3D homogenization approach to investigate the behavior of masonry arch bridges: The Venice trans-lagoon railway bridge, Construction and Building Materials, 66, 567-586, 2014.

[13] G. Milani, P.B. Lourenço, 3D non-linear behavior of masonry arch bridges, 
Computers \& Structures, 110, 111, 133150, 2012.

[14] G.A. Drosopoulos, G.E. Stavroulakis, C.V. Massalas, Limit analysis of a single span masonry bridge with unilateral frictional contact interfaces, Eng. Struct., 28(13),1864-73, 2006.

[15] P.J. Fanning, T.E. Boothby, Three dimensional modelling and full scale testing of stone arch bridges, Comput. Struct., 79(29-30), 2645-62, 2001.

[16] D.V. Oliveira, P.B. Lourenço, C. Lemos, Geometric issues and ultimate load of masonry arch bridges from the northwest Iberian Peninsula, Eng. Struct., 32(12), 3955-65, 2010.

[17] Y. Zhang, E. Tubaldi, L. Macorini, B.A. Izzuddin, Mesoscale partitioned modelling of masonry bridges allowing for arch-backfill interaction, Construction and Building Materials, 173, 820-842, 2018.

[18] Tubaldi E, Macorini L, Izzuddin BA. Three-dimensional mesoscale modelling of multi-span masonry arch bridges subjected to scour. Eng Struct 2018;165:486-500.

[19] I. Caliò, M. Marletta, B. Pantò, A new discrete element model for the evaluation of the seismic behaviour of unreinforced masonry buildings, Engineering Structures, 40, 327-338, 2012.

[20] B. Pantò, F. Cannizzaro, I. Caliò, P.B. Lourenço, Numerical and experimental validation of a 3D macro-model element method for the in-plane and out-ofplane behaviour of unreinforced masonry walls, International Journal of Architectural Heritage, 11(7), 946-964, 2017.

[21] B. Pantò, L. Giresini, M. Sassu, I. Caliò, Non linear modeling of masonry churches through a discrete macroelement approach, Earthquake and Structures, 12(2), 223-236, 2017.

[22] B.Pantò, F.Cannizzaro, S.Caddemi, I.Caliò, 3D macro-element modelling approach for seismic assessment of historical masonry churches, Advances in Engineering Software, 97, 40-59, 2016.

[23] S. Caddemi, I. Caliò, F. Cannizzaro and B. Pantò, New Frontiers on Seismic Modeling of Masonry Structures, Front. Built Environ, 2017.

[24] F. Cannizzaro, B. Pantò, S. Caddemi, I. Caliò, A Discrete Macro-Element Method (DMEM) for the nonlinear structural assessment of masonry arches, Engineering Structures, 168, 243-256, 2018.

[25] Gruppo Sismica, HiStrA software (Historical Structures Analysis) Release 4.6.0". Catania, Italy, September 2017.

[26] FEA Itd, LUSAS - Theory Manuals, Lusas Vertion 16.0.

[27] RFI, «Guide line RFI DIN ICI LG IFS $001 \mathrm{~A}$ "Linee guida per la verifica strutturale dei ponti ad arco in muratura"," 2006, in Italian. 